University of Nebraska - Lincoln

DigitalCommons@University of Nebraska - Lincoln

Faculty Publications from the Harold W. Manter Laboratory of Parasitology

2003

\title{
A PCR-ELISA for the Identification of Cyathostomin Fourth-Stage Larvae from Clinical Cases of Larval Cyathostominosis
}

\author{
J. E. Hodgkinson \\ Liverpool School of Tropical Medicine, jhodgkin@liverpool.ac.uk \\ J. Ralph Lichtenfels \\ Animal Parasitic Disease Lab, ARS, United States Department of Agriculture, 2jrcgl@gmail.com \\ T. S. Mair \\ Belle Equine Veterinary Clinic \\ P. Cripps \\ University of Liverpool \\ K. L. Freeman \\ University of Liverpool \\ See next page for additional authors
}

Follow this and additional works at: https://digitalcommons.unl.edu/parasitologyfacpubs

Part of the Parasitology Commons

Hodgkinson, J. E.; Lichtenfels, J. Ralph; Mair, T. S.; Cripps, P.; Freeman, K. L.; Ramsey, Y. H.; Love, S.; and Matthews, J. B., "A PCR-ELISA for the Identification of Cyathostomin Fourth-Stage Larvae from Clinical Cases of Larval Cyathostominosis" (2003). Faculty Publications from the Harold W. Manter Laboratory of Parasitology. 626.

https://digitalcommons.unl.edu/parasitologyfacpubs/626

This Article is brought to you for free and open access by the Parasitology, Harold W. Manter Laboratory of at DigitalCommons@University of Nebraska - Lincoln. It has been accepted for inclusion in Faculty Publications from the Harold W. Manter Laboratory of Parasitology by an authorized administrator of DigitalCommons@University of Nebraska - Lincoln. 


\section{Authors}

J. E. Hodgkinson, J. Ralph Lichtenfels, T. S. Mair, P. Cripps, K. L. Freeman, Y. H. Ramsey, S. Love, and J. B. Matthews 


\title{
A PCR-ELISA for the identification of cyathostomin fourth-stage larvae from clinical cases of larval cyathostominosis
}

\author{
J.E. Hodgkinson ${ }^{\mathrm{a}, *}$, J.R. Lichtenfels ${ }^{\mathrm{b}}$, T.S. Mair ${ }^{\mathrm{c}}$, P. Cripps ${ }^{\mathrm{d}}$, K.L. Freeman ${ }^{\mathrm{d}}$, \\ Y.H. Ramsey ${ }^{\mathrm{e}}$, S. Love ${ }^{\mathrm{e}}$, J.B. Matthews ${ }^{\mathrm{d}}$ \\ ${ }^{a}$ Department of Veterinary Parasitology, Liverpool School of Tropical Medicine, Pembroke Place, Liverpool L3 5QA, UK \\ ${ }^{\mathrm{b}}$ Parasite Biology, Epidemiology and Systematics Laboratory, Agricultural Research Service, US Department of Agriculture, Beltsville, MD 20705, USA \\ ${ }^{\mathrm{c}}$ Bell Equine Veterinary Clinic, Maidstone, Kent, UK \\ ${ }^{\mathrm{d}}$ Department of Veterinary Clinical Sciences and Animal Husbandry, University of Liverpool, Leahurst, South Wirral CH64 7TE, UK \\ ${ }^{\mathrm{e}}$ Institute of Comparative Medicine, University of Glasgow, Bearsden Road, Glasgow G61 1QH, UK
}

Received 20 March 2003; received in revised form 14 May 2003; accepted 30 May 2003

\begin{abstract}
We report the use of six oligoprobes designed from intergenic spacer region sequences to identify fourth-stage larvae (L4) of the tribe Cyathostominae. Oligoprobes were designed for identification of the following species: Cylicocyclus ashworthi, Cylicocyclus nassatus, Cylicocyclus insigne, Cyathostomum catinatum, Cylicostephanus goldi, and Cylicostephanus longibursatus. A seventh probe was designed as a positive control to identify all these members of the Cyathostominae. The intergenic spacer region was amplified by PCR using conserved primers. Initially, three oligoprobes were used in Southern blot analysis. To facilitate high-throughput identification, these and a further four oligoprobes were developed for use in a PCR-ELISA. All probes were validated for their ability to detect cyathostomin PCR products in the PCR-ELISA, using DNA from morphologically identified adult parasites. Initially, 712 L4 were isolated from the diarrhoeic faeces from horses $(n=17)$ with clinical larval cyathostominosis. PCR products from 522 of these L4 were subjected to analysis, with 413 L4 being identified as one of the aforementioned species. With reference to individual species analysis, $28.5 \%$ of the $522 \mathrm{~L} 4$ were identified as C. longibursatus, $25.7 \%$ as C. nassatus, $15.9 \%$ as C. ashworthi, $7.3 \%$ as $C$. goldi and $1.7 \%$ as C. catinatum. No L4 were identified as being C. insigne species. When L4 within faeces from individual horses were compared, no sample was found to comprise parasites of one species. The least number of species identified in a single sample was two. This study suggests that clinical larval cyathostominosis is predominantly caused by mixed-species infections.
\end{abstract}

(C) 2003 Australian Society for Parasitology Inc. Published by Elsevier Ltd. All rights reserved.

Keywords: Cyathostominosis; Horses; Intergenic spacer region; Nematoda/Strongylida; PCR-ELISA

\section{Introduction}

Cyathostomins (order Strongylida) are recognised as primary parasitic pathogens of horses (Love et al., 1999). These ubiquitous nematodes exist as a tribe of over 50 individual species within 13 genera (Lichtenfels et al., 1998; Matthee et al., 2002) and are differentiated on the basis of morphology of the head and tail of the adult parasite. These nematodes undergo a period of larval development in the wall of the caecum and colon, and are classified as early third-stage larvae (EL3), late third-stage

\footnotetext{
* Corresponding author. Tel.: +44-0151-705-3142; fax: +44-0151-7053373 .

E-mail address: jhodgkin@liverpool.ac.uk (J.E. Hodgkinson).
}

larvae and developing fourth-stage larvae. In heavily infected horses, the larvae can accumulate in large numbers $(100,000 \mathrm{~s})$, and it is presumed that the EL3 undergo a period of arrested development (Eysker et al., 1989, 1990). This is thought to occur prior to simultaneous reactivation of the larvae, which leads to a clinical syndrome known as larval cyathostominosis, a severe inflammatory enteropathy affecting the caecum and colon. The principal clinical effects of larval cyathostominosis are weight loss, diarrhoea and/or subcutaneous oedema, and there is a $50 \%$ case fatality rate despite intensive treatment (Giles et al., 1985; Love and McKeand, 1997). Larval cyathostominosis occurs more commonly in young horses in late winter/early spring, but there is life-long susceptibility to these nematodes, 
which can cause clinical disease at any age. In addition, cyathostomins have been associated with various types of equine colic (Uhlingher, 1990; Mair and Pearson, 1995; Murphy et al., 1997; Mair et al., 2000). Arrested larvae can persist for up to 2 years (Eysker et al., 1990), during which time the parasites have substantially reduced susceptibility to all anthelmintic compounds (Love and McKeand, 1997).

The detailed biology of both free-living and host stages of cyathostomins is not yet known at the individual species level. Furthermore, the role of individual cyathostomin species in the pathogenesis of mixed strongyle infection is not known. They cannot be classified to species as preparasitic stages, and there is a limited number of morphological features that allow identification of the parasitic larval stages (Dvojnos and Harcenko, 1990). Recently, molecular methods have been used to allow study at the individual species level (Gasser et al., 1996; Kaye et al., 1998; Hung et al., 1999; Hodgkinson et al., 2001). To investigate the relative importance of individual species, we have developed species-specific DNA probes for the identification of six common cyathostomins, Cylicocyclus ashworthi, Cylicocyclus insigne, Cylicocyclus nassatus, Cyathostomum catinatum, Cylicostephanus goldi and Cylicostephanus longibursatus. These probes are based on intergenic spacer (IGS) region sequences published previously (Kaye et al., 1998; Hodgkinson et al., 2001).

PCR-ELISA has become a popular research tool and has been applied across a range of research areas from detection of bacterial contamination in the food industry to the monitoring of parasitaemia in cattle (Gutierrez et al., 1997; Ge et al., 2002; Masake et al., 2002). This system of detection has advantages over conventional hybridisation techniques, including increased sensitivity, verification of integrity of amplicon and rapid analysis of multiple PCR assays simultaneously, as well as being suitable for routine diagnosis and automation (Ge et al., 2002; Masake et al., 2002; Wilson et al., 2002). Here, this technique has been exploited for the high-throughput species identification of fourth-stage larvae (L4) in the diarrhoeic faeces of cyathostomin-infected horses.

\section{Materials and methods}

\subsection{Genomic DNA extraction from parasites}

DNA was extracted from individual adult and L4 parasites by digestion at $55{ }^{\circ} \mathrm{C}$ overnight in $200 \mu \mathrm{l}$ of extraction buffer containing $200 \mathrm{mM}$ Tris $-\mathrm{HCl}(\mathrm{pH} 8.0), 50$ $\mathrm{mM}$ EDTA, $200 \mathrm{mM} \mathrm{NaCl}, 1 \% \mathrm{SDS}$ and $1 \mathrm{mg} / \mathrm{ml}$ Proteinase K. DNA was purified by two phenol/chloroform extractions, precipitated with ethanol and dissolved in $30 \mu \mathrm{l}$ deionised water prior to storage at $-20{ }^{\circ} \mathrm{C}$. DNA concentration was not measured routinely, as the amount of DNA obtained from small single larvae was often below the limit of detection of the spectrophotometer.

\subsection{Polymerase chain reaction amplification}

PCR reactions were carried out in $50 \mu \mathrm{l}$ reaction volumes using conserved primers (CY1 forward; $5^{\prime}$ GGT CAA GGT GTT GTA TCC AGT AGA G $3^{\prime}$ and CY18 reverse; $5^{\prime}$ CTT AGA CAT GCA TGG CTT AAT C $3^{\prime}$ ), which amplify the IGS region from at least 19 different species (Kaye et al., 1998; Hodgkinson et al., 2001). Amplification reactions contained $50 \mathrm{mM} \mathrm{KCl}, 10 \mathrm{mM}$ Tris $-\mathrm{HCl}$ (pH 8.3), $1.5 \mathrm{mM}$ $\mathrm{MgCl}_{2}, 200 \mu \mathrm{M}$ of each dNTP, $1.25 \mathrm{U}$ AmpliTaq Gold (Perkin Elmer Biosystems). The amount of genomic DNA template added to the reaction was $1 \mu$ l. However, if no amplicon was produced, the template was added at a dilution of 1:10 (i.e. $0.1 \mu \mathrm{l}$, to overcome the effects of any possible PCR-inhibitory substance in the sample) and at volumes of $3 \mu \mathrm{l}$ and $5 \mu \mathrm{l}$ (to overcome any possible problems with small amounts of DNA). In all cases, the amount of $\mathrm{H}_{2} \mathrm{O}$ added to the reactions was adjusted to ensure the same final concentration of all other reagents. If no amplicon was produced after adjustment of the amount of input template, a semi-nested PCR was carried out using a highly conserved primer CY26 (5' GAG CTG GGT TTA GAC CGT CGT GAG 3'), in combination with CY18 for the first round. In the second round amplifications, $0.5 \mu$ l of this product was subjected to PCR using the CY1 and CY18 primers. The cycling conditions for all primer combinations were: denaturation/Taq polymerase activation for $10 \mathrm{~min}$ at $94{ }^{\circ} \mathrm{C}$, denaturation at $94{ }^{\circ} \mathrm{C}$ for $1 \mathrm{~min}$, annealing at $60{ }^{\circ} \mathrm{C}$ for $1 \mathrm{~min}$ and extension at $72{ }^{\circ} \mathrm{C}$ for $2 \mathrm{~min}$ for 35 cycles, followed by a final extension at $72{ }^{\circ} \mathrm{C}$ for $10 \mathrm{~min}$. In all reactions, the appropriate negative and positive control samples were included: negative samples did not include DNA, while positive controls contained genomic DNA from a morphologically identified adult. In terms of specificity against non-cyathostomin species, the CY1/CY18 primers do not amplify IGS PCR products from Parascaris equorum or Oxyuris equi (Hodgkinson et al., 2001). These primers do amplify DNA from Triodontophorus serratus, Triodontophorus tenuicollis, Triodontophorus brevicaudata, Strongylus vulgarus and Strongylus edentatus (data not shown).

\subsection{Detection of PCR products by Southern blot analysis}

Southern blotting was performed as described previously using IGS PCR products from each L4 and digoxygenin, DIG-labelled oligonucleotide probes (Roche, DIG Oligonucleotide Tailing Kit) for C. longibursatus, C. nassatus and C. goldi (Hodgkinson et al., 2001). Five microlitres of each PCR product was run on an agarose gel and transferred to a nylon membrane. This membrane was probed with one of the three species-specific probes, stripped and re-probed with a second probe, and the process repeated for the third probe. Finally, the membrane was stripped and re-probed with a positive control probe. The sequences of the probes are shown in Table 1, along with the sequence of a probe that hybridises to IGS PCR products from all species of 
Table 1

The nucleotide sequence of six species-specific probes and a positive control probe

\begin{tabular}{|c|c|c|c|c|c|}
\hline \multirow[t]{2}{*}{ Cyathostomin species } & \multirow[t]{2}{*}{ Sequence of species-specific probe $\left(5^{\prime}-3^{\prime}\right)$} & \multirow[t]{2}{*}{$\begin{array}{l}\text { No. of } \\
\text { negative values }\end{array}$} & \multirow[t]{2}{*}{$\begin{array}{l}\text { No. of } \\
\text { positive values }\end{array}$} & \multicolumn{2}{|c|}{$\begin{array}{l}\text { Cut-off value } \\
\text { (OD } 405 \mathrm{~nm})\end{array}$} \\
\hline & & & & $15 \min$ & $30 \mathrm{~min}$ \\
\hline \multicolumn{6}{|l|}{ Cylicostephanus } \\
\hline longibursatus & GGAGAAATTGGTGGCGACT & 72 & 51 & 1.207 & 1.640 \\
\hline goldi & TCTTAGCATCAGGAGAAAT & 72 & 48 & 0.363 & 0.618 \\
\hline \multicolumn{6}{|l|}{ Cylicocyclus } \\
\hline nassatus & GCATCATACTGGTCCACAG & 72 & 44 & 0.215 & 0.337 \\
\hline ashworthi & TTGGTCTTACATAGAAAAT & 94 & 60 & 0.391 & 0.652 \\
\hline insigne & AATCATTGATTCTACATATACAA & 83 & 50 & 0.290 & 0.453 \\
\hline \multicolumn{6}{|l|}{ Cyathostomum } \\
\hline catinatum & TGTTTTCACTTAATACAATT & 75 & 47 & 0.259 & 0.453 \\
\hline
\end{tabular}

The OD value was determined for each probe at 15 and $30 \mathrm{~min}$, as indicated, and these values were used to establish the cut-off for each probe. 'negative values' are PCR-ELISA OD readings from PCR reactions that did not include DNA template. 'positive values' are PCR-ELISA OD readings from PCR reactions that include PCR product amplified from an adult of the homologous species. This table shows the number of OD values that were used in the statistical analysis to select the PCR-ELISA cut-off values for each probe.

cyathostomin examined so far (designated as the positive control probe). In all Southern blots, a positive control was incorporated that employed a PCR product from the DNA of a morphologically identified adult for each of the three species tested.

\subsection{Optimisation of the PCR-ELISA}

To increase the throughput of samples, PCR-ELISA was employed for the six species-specific probes and the positive control probe (Table 1). To test for cross-species hybridisation of the probes in this assay, 35 morphologically identified cyathostomin adults (Table 2) were used. For each species-specific probe, DNA from three individuals of the species homologous to the probe were used, whilst the remaining 32 individuals represented 11 heterologous cyathostomin species. In addition, the species-specific probes were tested against IGS PCR products generated from $T$. serratus, T. tenuicollis, T. brevicaudata, $S$. vulgarus or $S$. edentatus. To test each probe for intra-specific variation in the optical density (OD) obtained, several individuals of the corresponding species were analysed by PCR-ELISA (Table 2). In terms of amount of probe used, three concentrations ( $4 \mathrm{pmol} / \mathrm{ml}, 7.5 \mathrm{pmol} / \mathrm{ml}$ and $15 \mathrm{pmol} / \mathrm{ml}$ ) were tested (data not shown). For the assay, $7.5 \mathrm{pmol} / \mathrm{ml}$ of all capture probes was found to be optimum, with the exception of the $C$. catinatum probe, which was used at 15 $\mathrm{pmol} / \mathrm{ml}$. In addition, the amount of PCR products used in the ELISA was examined using $5 \mu \mathrm{l}$ and $1 \mu \mathrm{l}$ of neat PCR products and subsequent twofold serial dilutions of PCR product from an individual of the corresponding species. Five microlitres of neat PCR product was found to be optimum for use with each probe (data not shown). To establish cut-off values for each probe, appropriate positive and negative OD values from multiple assays were used.
The number and details of these assays are shown in Table 1. Descriptive statistical analyses were performed using the Minitab 13.1. programme. Discrete positive and negative OD values were obtained for all probes, except the $C$. catinatum probe. Hence, for five of the six species-specific probes, the cut-off value was determined as the arithmetic mean of the lowest known positive value and the highest known negative value. In the case of the $C$. catinatum probe, some overlap of OD values for known positive and negative samples were seen. For this probe, a cut-off value was determined as 3.7 standard deviations (log scale) for the negative controls (above which 0.0001 of the negatives should lie for a Normal distribution). The positive control probe cut-off value was determined as the lowest OD detected for a cyathostomin PCR product. The PCR-ELISA cut-off values for each probe are shown (Table 1). The cut-off values were used in the L4 analysis to define the species present.

\subsection{Collection of parasites}

Individual adult worms were collected from the large intestine of horses at a local abattoir. The worms were washed in $171 \mathrm{mM}$ phosphate-buffered saline, $\mathrm{pH}$ 7.2, (PBS), the parasite heads removed and the remainder of the parasites stored in liquid nitrogen. Nematode heads were cleared in phenol-alcohol (80\% melted phenol crystals and $20 \%$ absolute ethanol) in temporary wet mounts and identified with the aid of interference light microscopy at $400 \times$ magnification according to Lichtenfels et al. (1998).

Seventeen horses (Table 3) were identified as cases of larval cyathostominosis based on the presence of L4 in their faeces and/or clinical parameters. These cases were presented at the Philip Leverhulme Large Animal Hospital (University of Liverpool, UK), a 'referral center' or at an 
Table 2

The species of morphologically identified adults that were used in the PCR-ELISA validation experiments

\begin{tabular}{|c|c|c|c|}
\hline \multirow[t]{2}{*}{ Cyathostomin species } & \multicolumn{2}{|l|}{ Sample number of adult worms } & \multirow[t]{2}{*}{ No. of horses represented } \\
\hline & Inter-specific validation experiments & Intra-specific validation experiments & \\
\hline \multicolumn{4}{|l|}{ Cylicostephanus } \\
\hline longibursatus & $407,415,427 *$ & $401,463,496,615,798,618,626,707,712,735,740,800$ & 4 \\
\hline calicatus & $277,568,590$ & - & 1 \\
\hline goldi & $502 *, 429,439$ & $428,433,436,616,473,734,442,478,509$ & 3 \\
\hline \multicolumn{4}{|l|}{ Cylicocyclus } \\
\hline ashworthi & $305^{*}, 330,333$ & $365,399,371,328,332,334,353,376,329,337$ & 2 \\
\hline leptostomum & $356,345,461$ & - & 1 \\
\hline insigne & $454,680^{*}, 801$ & $804,456,672,686$ & 2 \\
\hline \multicolumn{4}{|l|}{ Cyathostomum } \\
\hline pateratum & $208,321,220$ & - & 1 \\
\hline catinatum & $299,402 *, 384$ & $449,205,411,216,652$ & 4 \\
\hline labratus & $303,304,307$ & - & 1 \\
\hline labiatus & $421,431,445$ & - & 1 \\
\hline \multicolumn{4}{|l|}{ Poteriostomum } \\
\hline imparidentatum & 482,483 & - & 1 \\
\hline \multicolumn{4}{|l|}{ Strongylus } \\
\hline edentatus & $806,810,811$ & - & 1 \\
\hline
\end{tabular}

A number was assigned to each adult at the time of identification and this is shown here. PCR products amplified from these individuals were used to test each probe for cross-hybridisation and intra-specific variation in OD values (see data in Fig. 2). *Indicates individuals used in the PCR-ELISA probe titration experiments.

equine 'first opinion' practice (Bell Equine Veterinary Clinic, Maidstone, Kent, UK). Nine cases were reported in 1999, five in 2000 and two in 2001. Most cases were reported from November to February, with two in May (2001) and one case in June (2000). Eleven horses were $<6$ years of age and the others $>15$ years (representing both sexes and a range of different breeds). Faecal samples varied in consistency from soft to watery. Worming history was difficult to ascertain and imprecise when available and is, therefore, not included in Table 3. L4, recognised by their lack of head characteristics present in adult stages, were harvested from faecal samples of all horses for isolation of DNA and subsequent analysis. Typically, $1 \mathrm{ml}$ sub-aliquots (from a 5-20 $\mathrm{ml}$ sample of faeces) were diluted in $9 \mathrm{ml}$ of PBS. Most L4 were detected macroscopically, whereas, some L4 were only visible under a microscope, in varying states of condition. Individual L4 were isolated and washed extensively in PBS, prior to storage at $-70{ }^{\circ} \mathrm{C}$. All L4 present were isolated from each sample. The number of individual worms harvested from each faecal sample varied from 10 to 111 (Table 3). In total, 712 L4 were isolated.

\subsection{Conditions used in the PCR-ELISA for identification of $L 4$}

For individual L4, PCR using the CY1 and CY18 primer combination was performed as described above, except that PCR DIG-labelling mix (Roche, $100 \mu \mathrm{M}$ dNTP) was used
Table 3

Details for 17 horses with larval cyathostominosis, including the number of fourth-stage larvae isolated from the diarrhoeic faeces of each horse

\begin{tabular}{lllllll}
\hline No. & $\begin{array}{l}\text { Age } \\
\text { (years) }\end{array}$ & Sex & $\begin{array}{l}\text { Time } \\
\text { (month) }\end{array}$ & Breed & $\begin{array}{l}\text { Disease } \\
\text { outcome }\end{array}$ & $\begin{array}{l}\text { No. L4 } \\
\text { isolated }\end{array}$ \\
\hline 1 & 3 & F & Nov & Da & D & 89 \\
2 & $>1$ & C & Nov & P & S & 36 \\
3 & 2 & F & Feb & TB & S & 36 \\
4 & 25 & M & Jan & X & D & 20 \\
5 & 3 & M & May & Sh & D & 39 \\
6 & 5 & M & June & nd & na & 48 \\
7 & 3 & M & Nov & Da & na & 26 \\
8 & 1.5 & F & Feb & CB & S & 15 \\
9 & $25+$ & M & Feb & Sh & S & 10 \\
10 & 25 & G & May & P & S & 44 \\
11 & 1.5 & G & Nov & P & S & 111 \\
12 & 15 & G & Nov & P & D & 34 \\
13 & 30 & G & Dec & TBX & D & 33 \\
14 & 2 & St & Jan & TB & D & 27 \\
15 & 1.5 & G & Nov & TBX & S & 20 \\
16 & nd & nd & nd & nd & na & 24 \\
17 & 1.5 & M & Dec & W & S & 100 \\
\hline
\end{tabular}

Samples were submitted from two practices: Bell Equine Veterinary Clinic, Maidstone, Kent, UK (numbers 1-13); Division of Equine Studies, Department of Veterinary Clinical Sciences and Animal Husbandry, University of Liverpool, Leahurst, South Wirral, UK (numbers 14-17).

nd, not determined; na, not available; F, filly; C, colt; M, mare; G, gelding; St, stallion; Da, Dales; $\mathrm{P}$, pony; TB, Thoroughbred; $\mathrm{X}$, crossbred; Sh, Shetland; CB, Cleveland Bay; W, Welsh; D, died; S, survived. 
for the incorporation of DIG-11-dUTP into the product. The six species-specific oligonucleotide sequences were labelled at the $5^{\prime}$ end with biotin and used as internal capture probes (Table 1). The reaction was performed according to the manufacturer's instructions (Roche). Five microlitres of DIG-labelled PCR product was run on an ethidium-bromide stained, $1 \%$ agarose gel using a $100 \mathrm{bp}$ ladder as a size standard (Gibco, BRL) and photographed upon UV transillumination. Only products detectable under these conditions were used in the PCR-ELISA. For every L4 tested, $5 \mu$ l of DIG-labelled PCR product were placed into each of seven wells in a standard 96 well plate (NUNC). Each $5 \mu \mathrm{l}$ PCR aliquot was denatured in situ for $10 \mathrm{~min}$ in $20 \mu \mathrm{l}$ denaturation solution prior to hybridisation with an oligonucleotide probe. Seven hybridisation buffers were prepared, each buffer containing one of the biotinylated species-specific probes and $225 \mu \mathrm{l}$ of each was mixed with one of the seven denatured PCR aliquots. Two hundred microlitres of each hybridisation mixture was transferred to one well of a microtitre plate coated with streptavidin (Roche) and incubated (with shaking) at $37{ }^{\circ} \mathrm{C}$ for $3 \mathrm{~h}$. Following five buffer washes, $100 \mu \mathrm{l}$ of a commercially available anti-DIG antibody conjugated with peroxidase (Roche) were added to each well $(1 \mathrm{mU} / \mu \mathrm{l}$ at 1:100 dilution, except for the $C$. catinatum probe, which was used at 1:50) and the plate incubated for $30 \mathrm{~min}$. Following five buffer washes, $200 \mu \mathrm{l}$ of the colourimetric substrate $\left(2,2^{\prime}\right.$ azino-di-[3-ethylbenzthiazoline sulphonate], ABTS) were added to each well and incubated at $37^{\circ} \mathrm{C}$, for $30 \mathrm{~min}$ (with shaking). The OD of the colour change was measured at 405 nm after 15 and 30 min using an Opsys MR microplate reader (Dynex). Binding of the biotin-labelled positive control probe was measured for all PCR products in each ELISA. As negative controls, PCR reactions, excluding DNA template, were used in each ELISA. For 3\% of L4, identification analysis was performed in two separate assays. For all L4, the result of the first assay was confirmed in the second experiment. Furthermore, L4 identified by Southern blot analysis as C. longibursatus (21 L4), C. goldi (7 L4) and $C$. nassatus (18 L4) were confirmed as the same species by subsequent PCR-ELISA.

\section{Results}

\subsection{Ability of the PCR-ELISA to detect cyathostomin PCR products}

A representative agarose gel, depicting the PCR amplicons from 35 adult cyathostomins and three S. edentatus adults, and their corresponding PCR-ELISA readings for the $C$. ashworthi probe are shown (Fig. 1). Readings for the positive control probe are also shown to indicate the presence of PCR product in all wells. Although some products showed weak amplification, as reflected in the banding pattern on gel electrophoresis, a positive signal was obtained in the PCR-ELISA. As we have established cut-off OD values for the positive control probe, future assays will not require prior gel electrophoresis, thus simplifying and speeding up the identification process. Only PCR products from the three homologous individuals (parasite numbers 305, 330, 333) gave OD readings above the determined cut-off value for the C. ashworthi probe (Fig. 1). Similar results were obtained for all species-specific probes, except that the $C$. longibursatus probe produced high background values when hybridised with PCR products from $C$. nassatus and $C$. goldi species, and this was reflected in the relatively high cut-off value for this probe (Table 1). Nevertheless, at the cut-off values selected, the ability of the assay to differentiate between similar sequences was exemplified by the $C$. ashworthi and $C$. catinatum probes. These probe sequences differed at only one nucleotide from other IGS sequences, yet did not show any cross-hybridisation to the other 11 cyathostomin species tested here. This demonstrated that the PCR-ELISA could discriminate between a single base mismatch in target sequences.

To test for intra-specific variation in OD values for each probe, the PCR-ELISA was performed with PCR products generated from several morphologically identified adults of the same species (Table 2). It should be noted that the C. ashworthi probe sequence reported previously (Hodgkinson et al., 2001) was found to hybridise to only two-thirds of all C. ashworthi individuals tested here (data not shown), reflecting a greater level of intra-specific variation in the target sequence. Thus, based on sequence analysis of IGS PCR products from six more C. ashworthi individuals, a new probe was designed. This was shown to hybridise to all C. ashworthi individuals tested, as indicated by the generation of OD values above the cut-off (Fig. 2).

\subsection{Identification of L4 by Southern blot analysis and/or PCR-ELISA}

The IGS region was amplified successfully by PCR from $546(76.7 \%)$ of the 712 L4 harvested. Despite the use of a range of volumes of template DNA in the PCR reactions and a semi-nested PCR approach, it was not possible to produce an amplicon for the other $166 \mathrm{~L} 4$. This lack of amplification may be due to the poor quality of some L4 recovered from faecal samples or the presence of PCR inhibitors in the extracted DNA. Alternatively, it is possible that these L4 are species of cyathostomin or other Strongylidae lacking conservation of the PCR primer sequences. Of the 546 L4 from which PCR products were obtained, 491 (90\%) were generated by the CY1/CY18 primer combination and 55 (10\%) by semi-nested PCR. Of the 546 L4 analysed by PCR-ELISA and/or Southern blot analysis, 522 products hybridised with the positive control probe. In total, products from $413(78.7 \%)$ of the 522 PCR products hybridised with one of the six species-specific probes, whilst the other $109(21.3 \%)$ hybridised only to the positive control probe. 


\section{(A)}

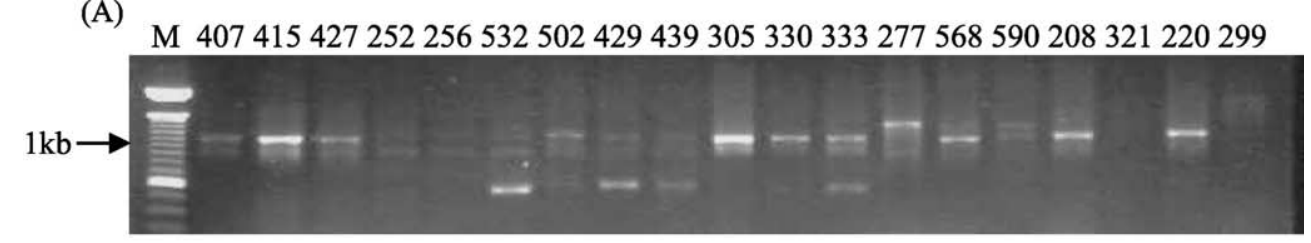

(B)

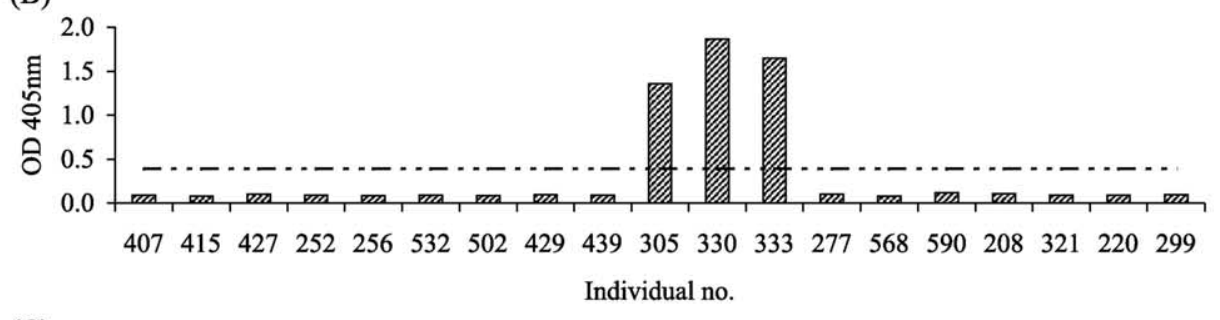

(C)
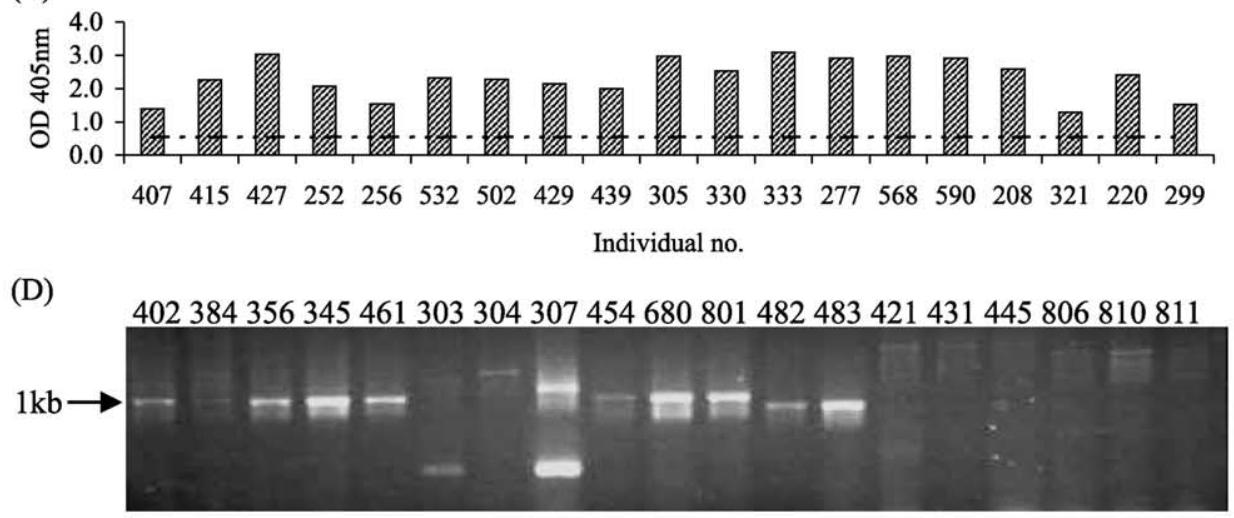

(E)

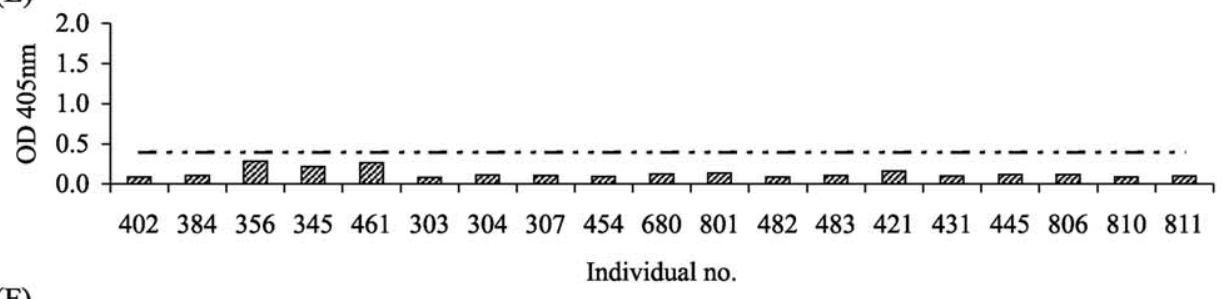

(F)

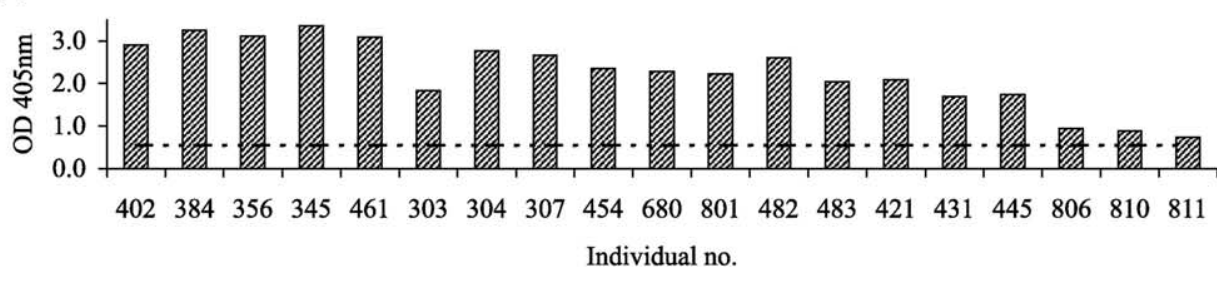

Fig. 1. (A and D) Representative gel electrophoresis of $5 \mu 1$ of CY1/CY18 PCR products generated from 38 individual worms of 12 strongyle species run on a $1 \%$ agarose gel. Products range in size from $600 \mathrm{bp}$ to $2 \mathrm{~kb}$. Lane M, $100 \mathrm{bp}$ ladder, lanes 407-811, number of adult worms (see Table 2 for species). (B and E) Graph showing corresponding PCR-ELISA OD values (405 nm, $15 \mathrm{~min}$ ), for individuals shown in (A) and (D) with C. ashworthi species-specific probe. (C and F) PCR-ELISA OD values (405 nm, $15 \mathrm{~min}$ ) for individuals shown in (A) and (D) with the positive control probe. Dotted lines indicate PCR-ELISA cut-off values.

The results of the analysis with the species-specific probes were as follows: $149(28.5 \%)$ C. longibursatus L4, 134 (25.7\%) C. nassatus L4, 83 (15.9\%) C. ashworthi L4, 38 (7.3\%) C. goldi L4 and $9(1.7 \%)$ C. catinatum L4. No larvae were identified as $C$. insigne. The species identified for individual horses are shown in Table 4. No one species was identified in the faeces of all 17 horses. Although, it could be argued that the number of different species identified within one sample may increase if larger numbers of L4 are examined, it was clear that even when small numbers of L4 were analysed, multiple species were detected. For example, only 19 L4 were identified from the faeces of horse 5, yet these represented five different species (Table 4). The percentage of horses in which the different species are 

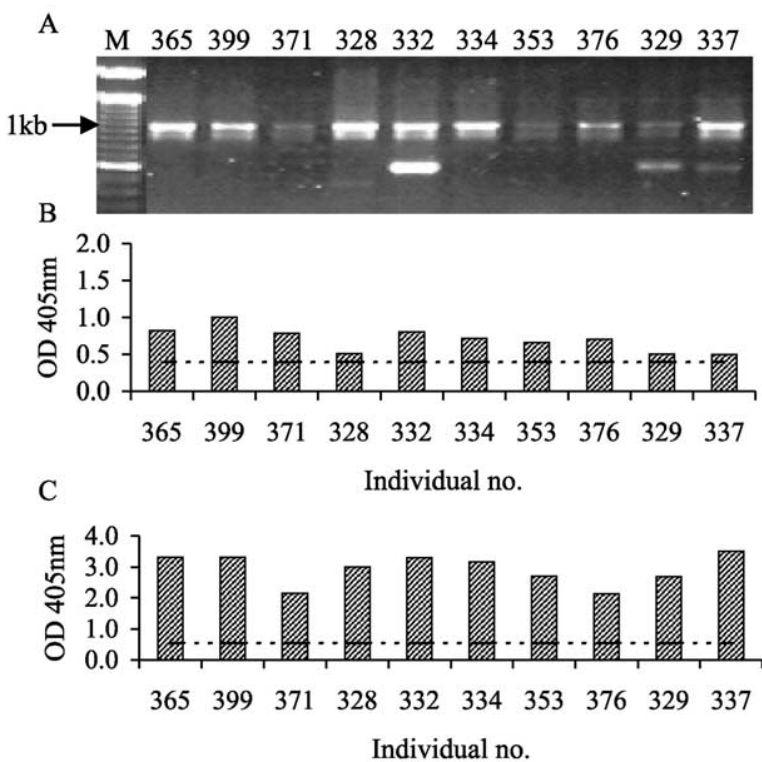

Fig. 2. (A) Gel electrophoresis of $5 \mu \mathrm{l}$ of PCR product generated by CY1/CY18 primers for 10 C. ashworthi individuals run on $1 \%$ agarose gel. Lane M, 100 bp ladder. Products for the 10 C. ashworthi individuals range in size from $600 \mathrm{bp}$ to $1 \mathrm{~kb}$. B. Graph showing corresponding PCR-ELISA OD values (405 nm, $15 \mathrm{~min}$ ) for products shown in (A) with C. ashworthi probe. (C) Graph showing PCR-ELISA OD values (405 nm, $15 \mathrm{~min}$ ) for products shown in (A) with positive control probe. PCR-ELISA cut-off values are indicated by the dotted lines.

present and the number of each species (as a percentage of the total L4 analysed by PCR-ELISA/Southern blot analysis) are shown in Table 5. Cylicostephanus longibursatus and C. nassatus were found in 14 of the 17 horses, whilst $C$. goldi was found in 13, C. ashworthi in 11 and C. catinatum in five horses. Although C. goldi was identified in samples from 13 horses, this species only represented $38 / 522(7.3 \%)$ of the total number of parasites analysed.

\section{Discussion}

This study constitutes the first application of molecular species identification to investigate clinical disease associated with cyathostomin infection in horses. Clinical diagnosis of this disease can be difficult and relies on various parameters (Giles et al., 1985; Reilly et al., 1993; Mair, 1994; Smets et al., 1999). Clinicians have previously ascribed variation in clinical signs to the presence of different cyathostomin species, level of larval burden or individual host immune response (Mair, 1994). However, no experimental data has been published to prove these theories. There have been attempts to identify species of L4 by post-mortem examination of clinical cases (Chiejina and Mason, 1977; Reinemeyer and Powell, 1986). In these studies, C. longibursatus, C. catinatum, Cylicocyclus radiatus and $C$. insigne L4 were observed. However, morphologically discriminating features of the L4 are limited and therefore, it is necessary that molecular methods be developed to identify these important stages in the parasite lifecycle.

The species examined here comprise the commonest species documented in previous studies, which identified adult parasites at post-mortem examination (Ogbourne, 1976; Mfitilodze and Hutchinson, 1990; Bucknell et al., 1995; Gawor, 1995). In these previous studies, between two and 21 species were reported in an individual horse, with a total of 27 species identified in any one study (Ogbourne, 1976; Mfitilodze and Hutchinson, 1990; Bucknell et al.,

Table 4

The number of L4 analysed by PCR-ELISA/Southern blot analysis for each horse

\begin{tabular}{|c|c|c|c|c|c|c|c|c|}
\hline Horse no. & No. L4 analysed & C. longibursatus & C. nassatus & C. goldi & C. ashworthi & C. insigne & C. catinatum & *Other species \\
\hline 1 & 76 & 4 & 17 & 2 & 38 & - & - & 15 \\
\hline 2 & 15 & 10 & 1 & - & 2 & - & - & 2 \\
\hline 3 & 32 & 27 & - & 4 & - & - & - & 1 \\
\hline 4 & 17 & 4 & 4 & 1 & 4 & - & - & 4 \\
\hline 5 & 19 & 4 & 3 & 3 & 2 & - & 1 & 6 \\
\hline 6 & 36 & 1 & 6 & 2 & 4 & - & 4 & 19 \\
\hline 7 & 18 & 2 & 11 & 2 & - & - & - & 3 \\
\hline 8 & 13 & - & 3 & - & 9 & - & - & 1 \\
\hline 9 & 8 & 2 & - & 2 & - & - & - & 4 \\
\hline 10 & 30 & 19 & 1 & 7 & - & - & - & 3 \\
\hline 11 & 79 & 32 & 22 & 6 & 6 & - & 1 & 12 \\
\hline 12 & 27 & 24 & - & 1 & - & - & - & 2 \\
\hline 13 & 24 & 6 & 5 & 1 & 10 & - & - & 2 \\
\hline 14 & 25 & - & 1 & - & 4 & - & - & 20 \\
\hline 16 & 14 & 1 & 7 & - & 2 & - & - & 4 \\
\hline 17 & 73 & 13 & 47 & 1 & 2 & - & 1 & 9 \\
\hline Total & 522 & 149 & 134 & 38 & 83 & 0 & 9 & 109 \\
\hline
\end{tabular}

The total number identified by each of the six species-specific probes is shown. *Indicates the number of L4 that hybridised with the positive control probe but not with any of the species-specific probes. 
Table 5

The number of horses (of 17) in which each species was present and the percentage of horses in which each cyathostomin species was identified are shown

\begin{tabular}{lll}
\hline $\begin{array}{l}\text { Cyathostomin } \\
\text { species }\end{array}$ & $\begin{array}{l}\text { No. horses in which each } \\
\text { species present }\end{array}$ & $\begin{array}{l}\text { No. L4 of given species } \\
\text { as a \%total L4 analysed }\end{array}$ \\
\cline { 2 - 3 } & $\begin{array}{l}\text { Total no. \% Total no. } \\
\text { of horses of horses }\end{array}$ & \\
\hline
\end{tabular}

\begin{tabular}{lllr}
$\begin{array}{l}\text { Cylicostephanus } \\
\text { longibursatus }\end{array}$ & 14 & 82.4 & 28.5 \\
goldi & 13 & 76.4 & 7.3 \\
$\begin{array}{c}\text { Cylicocyclus } \\
\text { nassatus }\end{array}$ & 14 & 82.4 & \\
$\begin{array}{l}\text { ashworthi } \\
\text { insigne }\end{array}$ & 11 & 64.7 & 15.9 \\
Cyathostomum & None & None & None \\
catinatum & 5 & & \\
\hline
\end{tabular}

The proportion of L4 identified, (as a percentage of the $522 \mathrm{~L} 4$ analysed), is shown for each species.

1995; Gawor, 1995). One study reported $90 \%$ of the total cyathostomin burden to be comprised of C. longibursatus, C. nassatus, C. catinatum, Cylicostephanus minutus and C. goldi species (Ogbourne, 1976). Later studies consistently supported the presence of these species with several others, including Cylicostephanus calicatus, Coronocyclus coronatum, Cylicocyclus leptostomum, C. insigne and Cyathostomum pateratum (Mfitilodze and Hutchinson, 1990; Bucknell et al., 1995; Gawor, 1995; Silva et al., 1999). In our study, C. longibursatus and C. nassatus were the commonest species identified, however, in contrast to the previous reports, $C$. catinatum were found in a small number of horses (five) and only represented $1.7 \%$ of the total population analysed. This may reflect geographic or seasonal trends in the presence of this species. Interestingly, C. insigne was not detected in this study, which does not support the particular association of this species with larval cyathostominosis (Reinemeyer and Powell, 1986). It is difficult to compare the proportion of $C$. ashworthi detected here with earlier studies, because this species has previously been confused morphologically with $C$. nassatus, which might have affected the relative reported incidence of these two species. Recently, C. ashworthi was identified as distinct from $C$. nassatus at both the morphological and genetic levels (Hung et al., 1997; Lichtenfels et al., 1997). Cylicostephanus goldi was found in several horses, but in smaller numbers than either C. longibursatus or C. nassatus, which is consistent with studies by Ogbourne (1976) and Bucknell et al. (1995).

Of the 546 L4 isolated, a PCR product amplified from 24 individuals did not hybridise to the positive control probe or to any of the species-specific probes. These may represent cyathostomin species, which lack the sequence encoding this probe. However, this region has been shown to be conserved for at least 19 cyathostomin species (Kaye et al., 1998; Hodgkinson et al., 2001). Alternatively, it may be that these L4 are non-cyathostomin species, such as S. vulgaris and $T$. tenuicollis. It has been observed that the CY1/CY18 primer set amplify PCR products from these species but these products do not hybridise with the positive control probe (data not shown).

Analysis of the data indicated that there was no association between the species identified and the outcome of disease or severity of diarrhoea in individual horses (Tables 3 and 4). In addition, the species composition was similar at both geographical locations. We accept that the numbers of individual parasites examined per horse may not give a representation of the total parasite population present, as in some cases only small numbers of L4 were isolated from the total volume of faeces examined. It should be noted, however, that in many faecal samples, multiple species were identified, for example, five different species were reported in 19 L4 isolated from case 5 (Table 4). Although different numbers of larvae were isolated from horses in this study and in some cases the number of larvae was small, conclusions on the number and proportion of species present can be drawn. The data reported here supports the proposal that the common species of cyathostomins play a role in clinical disease and does not suggest a primary role for any one species. In fact, the severity of clinical disease may be associated with factors such as individual host inflammatory/immune responses or grazing behaviour, which might affect the number of larvae that are ingested. In this study, L4 were obtained at a point in time when disease was already established. It is, therefore, possible that single species are involved in triggering the initial reactivation of $\mathrm{L} 4$ from the mucosa. To address this, it would be necessary to produce single-species infections. However, this is time-consuming, would require large numbers of experimental horses and would be impossible to predict the precise onset of larval reactivation. Given that the five species examined here comprised the majority of L4 present, it is likely that larval cyathostominosis is predominantly caused by mixed-species infections. The current success of this PCR-ELISA in identifying species using L4 genomic DNA, in addition to its high-throughput potential, lends it to widespread use in the investigation of cyathostomin basic biology, epidemiology and the role of different species in the development of drug resistance.

\section{Acknowledgements}

We would like to acknowledge the Horserace Betting Levy Board for generously funding this project and Patricia A. Pilitt, Parasite Biology, Epidemiology and Systematics Laboratory, Agricultural Research Service, US Department of Agriculture, USA for expert assistance in the preparation 
of heads of adult nematodes for microscopic identification. J.B.M. is funded by the ILPH.

\section{References}

Bucknell, D.G., Gasser, R.B., Beveridge, I., 1995. The prevalence and epidemiology of gastrointestinal parasites of horses in Victoria, Australia. Int. J. Parasitol. 25, 711-724.

Chiejina, S.N., Mason, J.A., 1977. Immature stages of Trichonema spp. as a cause of diarrhoea in adult horses in spring. Vet. Rec. 100, 360-361.

Dvojnos, G.M., Harcenko, V.A., 1990. Morphology and differential diagnostics of parasitic larvae of some Strongylidae (Nematoda) of horses. Angew. Parasitol. 31, 15-28.

Eysker, M., Boersema, J.H., Kooyman, F.N., 1989. Emergence from inhibited development of cyathostome larvae in ponies following failure to remove them by repeated treatments with benzimidazole compounds. Vet. Parasitol. 34, 87-93.

Eysker, M., Boersema, J.H., Kooyman, F.N., 1990. Seasonally inhibited development of cyathostome nematodes in Shetland ponies in The Netherlands. Vet. Parasitol. 36, 259-264.

Gasser, R.B., Stevenson, L.A., Chilton, N.B., Nansen, P., Bucknell, D.G., Beveridge, I., 1996. Species markers for equine strongyles detected in intergenic rDNA by PCR-RFLP. Mol. Cell. Probes 10, 371-378.

Gawor, J.J., 1995. The prevalence and abundance of internal parasites in working horses autopsied in Poland. Vet. Parasitol. 58, 99-108.

Ge, B., Zhao, S., Hall, R., Meng, J., 2002. A PCR-ELISA for detecting Shiga toxin-producing Escherichia coli. Microbes Infect. 4, 285-290.

Giles, C.J., Urquhart, K.A., Longstaffe, J.A., 1985. Larval cyathostomiasis (immature trichonema-induced enteropathy): a report of 15 clinical cases. Equine Vet. J. 17, 196-201.

Gutierrez, R., Garcia, T., Gonzalez, I., Sanz, B., Hernandez, P.E., Martin, R., 1997. A quantitative PCR-ELISA for the rapid enumeration of bacteria in refrigerated raw milk. J. Appl. Microbiol. 83, 518-523.

Hodgkinson, J.E., Love, S., Lichtenfels, J.R., Palfreman, S., Ramsey, Y.H., Matthews, J.B., 2001. Evaluation of the specificity of five oligoprobes for identification of cyathostomin species from horses. Int. J. Parasitol. 31, 197-204.

Hung, G.C., Chilton, N.B., Beveridge, I., McDonnell, A., Lichtenfels, J.R., Gasser, R.B., 1997. Molecular delineation of Cylicocyclus nassatus and C. ashworthi (Nematoda: Strongylidae). Int. J. Parasitol. 27, 601-607.

Hung, G.C., Gasser, R.B., Beveridge, I., Chilton, N.B., 1999. Speciesspecific amplification by PCR of ribosomal DNA from some equine strongyles. Parasitology 119, 69-80.

Kaye, J.N., Love, S., Lichtenfels, J.R., McKeand, J.B., 1998. Comparative sequence analysis of the intergenic spacer region of cyathostome species. Int. J. Parasitol. 28, 831-836.

Lichtenfels, J.R., Kharchenko, V.A., Sommer, C., Ito, M., 1997. Key characters for the microscopical identification of Cylicocyclus nassatus and Cylicocyclus ashworthi (Nematoda, Cyathostominae) of the horse, Equus caballus. J. Helminthol. Soc. Wash. 64, 120-127.

Lichtenfels, J.R., Kharchenko, V.A., Krecek, R.C., Gibbons, L.M., 1998. An annotated checklist by genus and species of 93 species level names for 51 recognized species of small strongyles (Nematoda: Strongyloidea: Cyathostominea) of horses, asses and zebras of the world. Vet. Parasitol. 79, 65-79.

Love, S., McKeand, J.B., 1997. Cyathostomosis: practical issues of treatment and control. Equine Vet. Educ. 9, 253-256.

Love, S., Murphy, D., Mellor, D., 1999. Pathogenicity of cyathostome infection. Vet. Parasitol. 85, 113-122.

Mair, T.S., 1994. Outbreak of larval cyathostomiasis among a group of yearling and two-year-old horses. Vet. Rec. 135, 598-600.

Mair, T.S., Pearson, G.R., 1995. Multifocal non-strangulating infarction associated with larval cyathostomiasis in a pony. Equine Vet. J. 27, $154-155$.

Mair, T.S., Sutton, D., Love, S., 2000. Caecocaecal and caecocolic intussusception associated with larval cyathostomosis in four young horses. Equine Vet. J. Suppl. 32, 77-80.

Masake, R.A., Njuguna, J.T., Brown, C.C., Majiwa, P.A.O., 2002. The application of PCR-ELISA to the detection of Trypanosoma brucei and T. vivax infections in livestock. Vet. Parasitol. 105, 179-189.

Matthee, S., Krecek, R.C., Gibbons, L.M., 2002. Cylicocyclus asini n. sp. (Nematoda: Cyathostominae) from donkeys Equus asinus in South Africa. Syst. Parasitol. 51, 29-35.

Mfitilodze, M.W., Hutchinson, G.W., 1990. Prevalence and abundance of equine strongyles (Nematoda: Strongyloidea) in tropical Australia. J. Parasitol. 76, 487-494.

Murphy, D., Keane, M.P., Chandler, K.J., Goulding, R., 1997. Cyathostome-associated disease in the horse: investigation and management of four cases. Equine Vet. Educ. 9, 247-252.

Ogbourne, C.P., 1976. The prevalence, relative abundance and site distribution of nematodes of the subfamily Cyathostominae in horses killed in Britain. J. Helminthol. 50, 203-214.

Reilly, G.A.C., Cassidy, J.P., Taylor, S.M., 1993. Two fatal cases of diarrhoea in horses associated with larvae of the small strongyles. Vet. Rec. 132, 267-268.

Reinemeyer, C.R., Powell, H.S., 1986. Larval cyathostomiasis in three horses in Tennessee. In: 29th Annual Proceedings, American Association of Veterinary Laboratory Diagnosticians. p. 69-76.

Silva, A.V., Costa, H.M., Santos, H.A., Carvalho, R.O., 1999. Cyathostominae (Nematoda) parasites of Equus caballus in some Brazilian states. Vet. Parasitol. 86, 15-21.

Smets, K., Shaw, D.J., Deprez, P., Vercruysse, J., 1999. Diagnosis of larval cyathostominosis in horses in Belgium. Vet. Rec. 144, 665-668.

Uhlingher, C.A., 1990. Effects of three anthelmintic schedules on the incidence of colic in horses. Equine Vet. J. 22, 251-254.

Wilson, T., Carson, J., Bowman, J., 2002. Optimisation of one-tube PCRELISA to detect femtogram amounts of genomic DNA. J. Microbiol. Methods 51, 163-170. 